\title{
KAYAPÓ KUKRÃDJÀ: MANIFESTAÇÕES CULTURAIS DOS POVOS INDÍGENAS
}

\section{Ana Paula Lívero Sampaio ${ }^{1}$}

\section{Veruska Pobikrowska Tardivo}

RESUMO: O presente trabalho tem como objetivo levantar dados e características no que se referem aos povos indígenas Kayapó, se propondo a observar o mítico, o simbólico, a significação presente na cultura, costumes e política dos Mebengokrê. Partindo desse pressuposto procurou-se compreender a relação com a conservação dos territórios indígenas, suas manifestações culturais, rituais, culinária e a imagem artística como meio de expressão, assim como a pintura corporal e os artefatos indígenas que permeiam a sua vida social. Pertencentes a família lingüística Jê, se consolidam em 19 (dezenove) comunidades, ocupando um território de 11 (onze) milhões de hectares entre os estados de Mato Grosso e Pará, no coração da floresta Amazônia brasileira.

\footnotetext{
${ }^{1}$ Acadêmica do $4^{\circ}$ Semestre de Arquitetura e Urbanismo, UNEMAT- Universidade do Estado de Mato Grosso, Campus de Barra do Bugres. aninhasamp@hotmail.com

2 Professora Mestre, do curso de Arquitetura e Urbanismo da UNEMAT - Universidade do Estado de Mato Grosso, campus de Barra do Bugres. veruska.tardivo@yahoo.com.br
} 
Palavras-chave: Kayapó. Cultura. Povos indígenas.

\section{INTRODUÇÃO}

O respectivo artigo se refere à descrição dos valores culturais étnicos do povo indígena Kayapó, com objetivo de orientar outro olhar sobre cultura fundamentado no reconhecimento e compreensão das diferentes maneiras de entender e posicionar-se no mundo. Partindo do pressuposto de que não se respeita o que não se conhece, objetiva-se com este estudo pesquisar a cultura indígena Kayapó. O termo "kayapó" usado no século XIX por grupos vizinhos possui o significado em seu dialeto de "aqueles que se parece com macacos", que possivelmente originou-se de um ritual, o qual os homens enfeitados com máscaras de macacos, executam danças curtas. Apesar de que se referem a si mesmos como Mebengokre, "os homens a partir do furo de água." (TURNER, 1991)

O grupo pertence à família lingüística Jê, que se deriva do tronco MacroJê. A língua Portuguesa é presente nas comunidades de acordo com a variante de contato, grau de isolamento e a história de cada grupo. $O$ território se localiza no Planalto Central brasileiro, aproximadamente 400 metros acima do nível do mar, ocupando os estados de Mato Grosso, em sua região norte e, o sul do Pará (TURNER, 1991). As terras oficialmente demarcadas cobrem uma área de 11 milhões de hectares do sudeste amazônico e formam assim a maior área protegida de floresta tropical no mundo (Zimmerman et al. 2001). Os Mebengokre se dividem em 19 comunidades, com uma população de 5.923 habitantes (FUNASA, 2006).

Observa-se a civilização Kayapó, como verdadeiros exemplos de diversidade cultural, compreendendo a relação existente entre sua arte, 
costumes, modo de vida, política e uma grandiosa harmonia com meio ambiente se tornando fantásticos guardiões de seus territórios tradicionais.

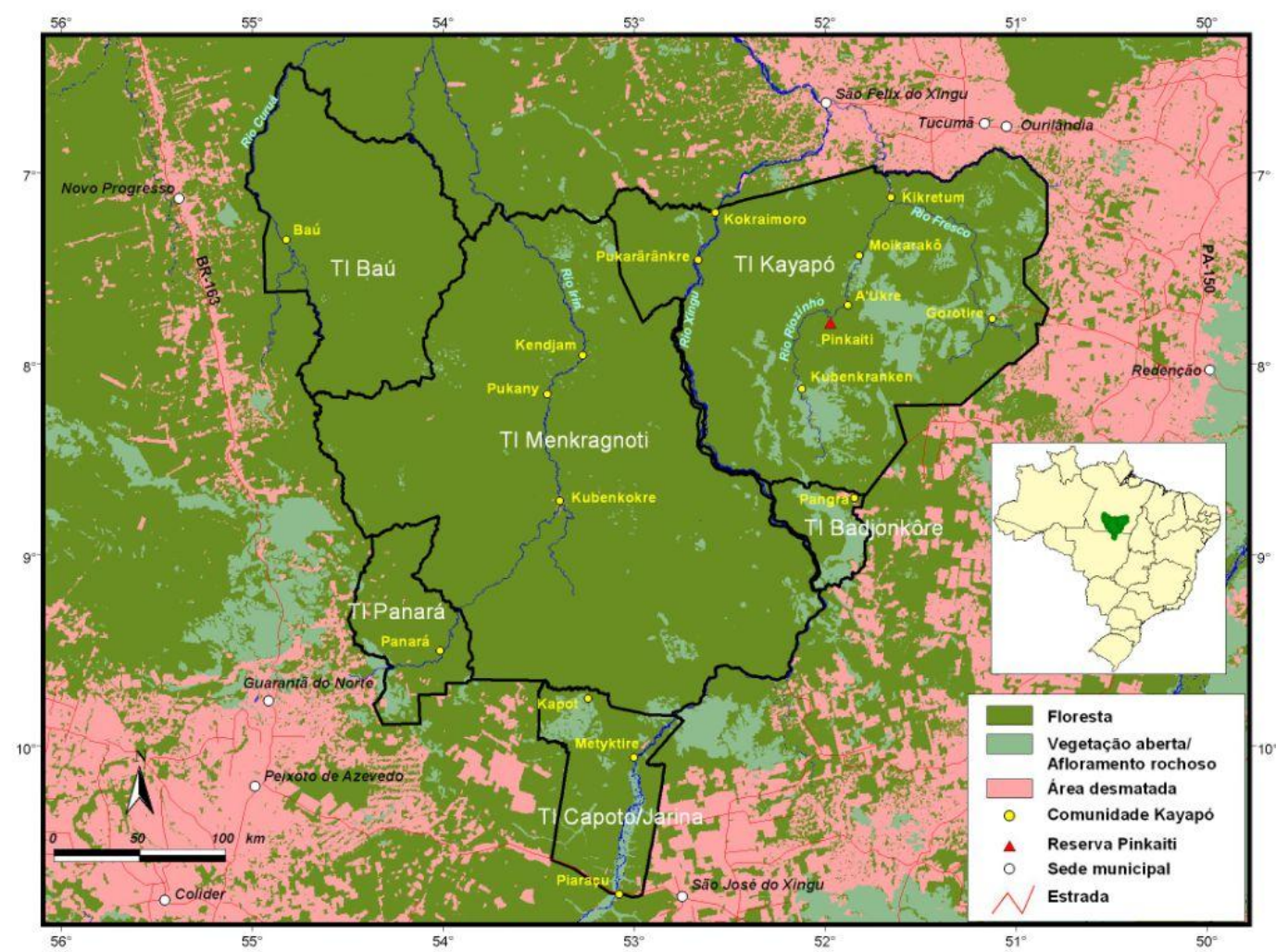

Figura 1-Localização das Terras Indígenas Kayapó (Conservation International do Brasil,2009).

\section{CONSERVAÇÃO DOS TERRITÓRIOS INDÍGENAS}

Atualmente, as terras indígenas são basicamente a única barreira contra a onda de desmatamento que vem devastando o sudeste da Amazônia, onde florestas dão lugar à agricultura. Este efeito de barreira ocorre porque os povos indígenas que dependem da floresta para sua sobrevivência, lutam ativamente por seus direitos territoriais e expansão de suas fronteiras. 
As terras Kayapó são particularmente valiosas para conservação, devido ao entrelaçamento de densas áreas de mata amazônica e áreas do cerrado brasileiro. Várias espécies de animais vertebrados tipicamente raros em áreas de cerrado e florestas transicionais são encontradas relativamente em alta densidade em terras dos Mebengokrê.

Espécies de grande porte, preferidas pelas comunidades locais por toda a Amazônia, são abundantes dentro das áreas de caça das comunidades Kayapó. A relativa alta densidade de muitas dessas espécies de consumo, como mutum-de-penacho (Crax fasciolata) e porco do mato (Tayassu pecari), indica que o ecossistema não foi severamente impactado pela caça, provavelmente porque as áreas sem caça, que funcionam como constante fonte de indivíduos para essas espécies são muito amplas. De fato, nenhuma outra grande reserva de floresta no sudeste amazônico, presentemente, protege tal complexo ecologicamente sensível de vida silvestre e a transição completa de vegetação desde o cerrado até as florestas densas (Zimmerman et al. 2001).

\section{ARTE, COSTUME E CULTURA KAYAPÓ}

As sociedades indígenas estão plenamente integradas na experiência social. A arte em certo ponto é anônima, no sentido em que o sujeito criador é coletividade, ainda que seja sempre o indivíduo concreto quem dá a marca ao artefato artístico imantando-o com as suas sensações, anseios e momento.

As culturas, em geral, e não apenas as artes constituem os grandes alicerces de sentido que permitem às comunidades humanas se auto afirmar, manter, argumentar e transformar. A arte está relacionada ao mítico, ao simbólico, ao sistema de poder, ao terapêutico, permeando toda a vida social. No domínio da arte, enfatiza-se o formal, a aparência, a imagem, como meio de expressão. 
Para os indígenas, não apenas são objetos para serem contemplados, o que se fabrica tem que ser bonito e, além de bonito, bom, pois assim se entende que foi feito segundo as regras da cultura, pois permite viver da maneira como os parentes escolheram viver. Desta maneira, a ênfase na novidade é pequena, mas não desaprovada. A novidade é bela quando pode ser integrada ao estilo pré-existente do grupo. O artista é aquele que consegue sempre criar coisas novas dentro do padrão particular de sua cultura. Isso significa que seu estilo gestual, dramático, visual ou auditivo, as artes e os cantos que inventa, sempre serão reconhecidos, pelos seus, como parte da criatividade do grupo.

A sociedade Kayapó se considera parte integrante de um mundo circular e vêem o processo do universo e da vida como cíclico, os ciclos do tempo ecológico e estrutural que determinam e acompanham a vida e as atividades humanas. Os Kayapó, homens e mulheres desempenham suas atividades, independentes enquanto grupos, e espacialmente separados.

Se localiza no meio do pátio, a casa dos homens, lugar onde eles se reúnem para discutir suas tarefas cotidianas, fabricarem seus artefatos e objetos dos rituais. As mulheres, por sua vez, agrupadas em uma sociedade, ocupam durante as suas conversas e atividades de pintura corporal coletiva a casa onde se dedicam a esses trabalhos. (TURNER, 1991).

\section{PINTURA CORPORAL}

Com relação à pintura dos Mebengokrê, dentre todas as cores que envolvem o universo cromático desses índios considera-se muito importantes o preto e vermelho. Essas cores envolvem um sentido muito particular, de tal maneira, arraigado culturalmente que se manifesta inconscientemente. (BELTRÃO, 1977). 
Consciente de sua dupla natureza, o índio tem consciência de que o homem é um ser puro manchado pela sua condição física. Esta noção se manifesta pela dualidade de sentido da cor vermelha que representa o sangue, símbolo de materialidade, sendo esse um pigmento extraído do urucum e representativo da cultura.

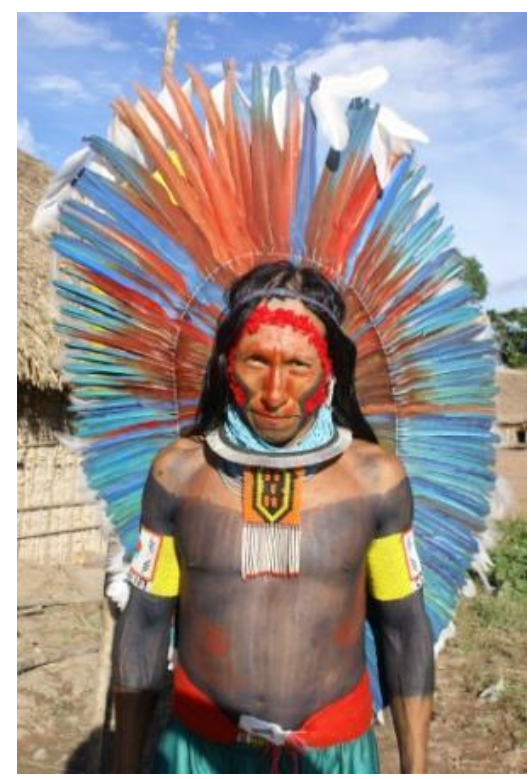

Figura 2- Pintura Corporal realizada na festa dos Homens, aldeia Kubenkokre (Luis Carlos S. Sampaio, 2010).

No corpo, o sangue corre seguindo um traçado natural das veias e artérias. Mas sobre o corpo o homem "realiza a arte" com desenhos em vermelho, testemunha de uma vida social intensa, como só os índios sabem executar. Essa pintura corporal é completada pelo preto, cor da criatividade, que é o outro aspecto da natureza humana.

As tintas mais comuns utilizadas na pintura corporal pelos índios brasileiros são fabricadas com a polpa de urucum (vermelho), jenipapo, fuligem de carvão (preto), tabatinga (branco), argila sedimentar, mole com certo teor de matéria orgânica. A primeira referência dessas cores data do descobrimento do Brasil se deve ao escrivão Pero Vaz que ao descrever na célebre carta dos costumes do Tupi do litoral, (BELTRÃO, 1977). Por ocasião de cerimônias e 
competições intertribais essas cores aparecem em toda sua plenitude, numa gama de desenhos que não se repetem.

No que diz respeito à pintura com urucum e jenipapo, a fabricação da cor vermelha retirada das sementes do urucuzeiro. Depois de retirada a casca do fruto, as sementes ficam de molho durante um dia. Em seguida são passadas na peneira e levadas ao fogo, onde permanecem por quarenta e oito horas. Nessa fase de preparação, a mulher Kayapó alternadamente retira e coloca no fogo a panela. Ao adquirir o urucum a consistência de pasta, ele é derramado ainda quente sobre um pano e enrolado. Ao esfriar apresentará uma tonalidade amarela ou vermelha escura, dependendo da variedade ultilizada para a pintura.

Os índios Kayapó não apreciam o jenipapo (do tupi ñandi'pab) como alimento, mas o utilizam na fabricação da tinta. O fruto é colhido ainda verde, ralado e depois de espremida, a massa é colocada na panela apenas para esquentar. O líquido fica então em repouso por um dia. Findo esse prazo está pronto para ser usado e misturado ao carvão adquirindo, assim, a tonalidade preta. Entretanto esse processo vem sofrendo mudanças em que ocorre o preparo sem utilização do fogo. As pinturas de jenipapo e urucum são feitas simplesmente com as mãos e pedaços finos de bambu, não se utilizando qualquer processo mecânico. As mulheres realizam as pinturas, fazendo um trabalho de incrível habilidade e rapidez, elas molham na boca a ponta do pedaço de bambu que utilizam para pintar. A saliva misturada ao jenipapo ou urucum dá uma consistência mais homogênea à tinta para que, por fim, possam aplicar à pele.

Alguns autores sustentam que a aplicação do urucum sobre a epiderme protege contra a ação actínica do sol e a picada de insetos. (LOPES, 1995). Revelam até que experiências provaram que uma das propriedades do urucum é tornar moderada a absorção do calor solar pelo corpo. Geralmente, o urucum é aplicado em determinadas partes do corpo e já o jenipapo é usado tanto para 
untar o corpo inteiro, como em partes especificamente determinadas rotambém.

A pintura corporal Kayapó e suas imagens pictóricas abstratas são admiradas pelo mundo afora. A sofisticação de sua arte causa surpresa para aqueles que não esperam encontrar tamanha beleza e elegância fora dos grandes centros urbanos. Percebe-se, porém que essa beleza e elegância coexistem simultaneamente na floresta.

\section{ARTE DO CABELO KAYAPÓ}

Em relação ao penteado e ao corte de cabelo, eles não se constituem, para o índio, apenas uma questão de higiene e de aparência pessoal, como ocorre em nossa sociedade atual. Essas atividades, aparentemente de cunho vaidoso, têm para os indígenas significado social e religioso.

De acordo com o estudo feito pela antropóloga Vilma Shiara, observa-se que tanto o cabelo como as aparas são elementos que adquirem em todas as sociedades um aspecto simbólico, relacionado à condição biológica do homem e ás suas aspirações puramente culturais. Segundo Shiara, o traço biológico marcante e sua importância social cultural devem ser ressaltados, advindos do fato de ele oferecer condições, devido à plasticidade e receber uma forma através de tratamento cultural, tornando-se assim um distintivo social. Para ela, "as aparas de cabelo" destacam-se desse elemento que expressa tanta uma integração absoluta, como uma rejeição social, adquire também valores que devem ser analisados no contexto cultural que lhe é próprio. Os cabelos devem ser continuamente aparados, atados, etc. Que demonstra ser um elemento renitente, biológico ou natural por excelência. Através dele a cultura reitera a sua presença como coordenadora da natureza. 
O que dá aos cabelos a sua importância semântica é a posição articulatória entre o estado biológico e o tratamento cultural, associando-os a situações sociais também articulatórias, tais como iniciações, passagem de classe de idade, nascimento, morte, viúves, etc.. Nesse sentido, a forma do cabelo se liga a cerimônias em todas as tribos brasileiras, com maior ou menor significado.

As mulheres da tribo Kayapó conservam seus cabelos compridos, mas aparados na frente com suas próprias mãos arrancando fio por fio em linha reta sobre a forma de franja, ficando sobre a forma triangular acima dos olhos. Arrancar os cabelos é o modo mais drástico de retirá-los, por motivos vários, o elemento ambíguo ou que manifesta a condição biológica da sociedade.

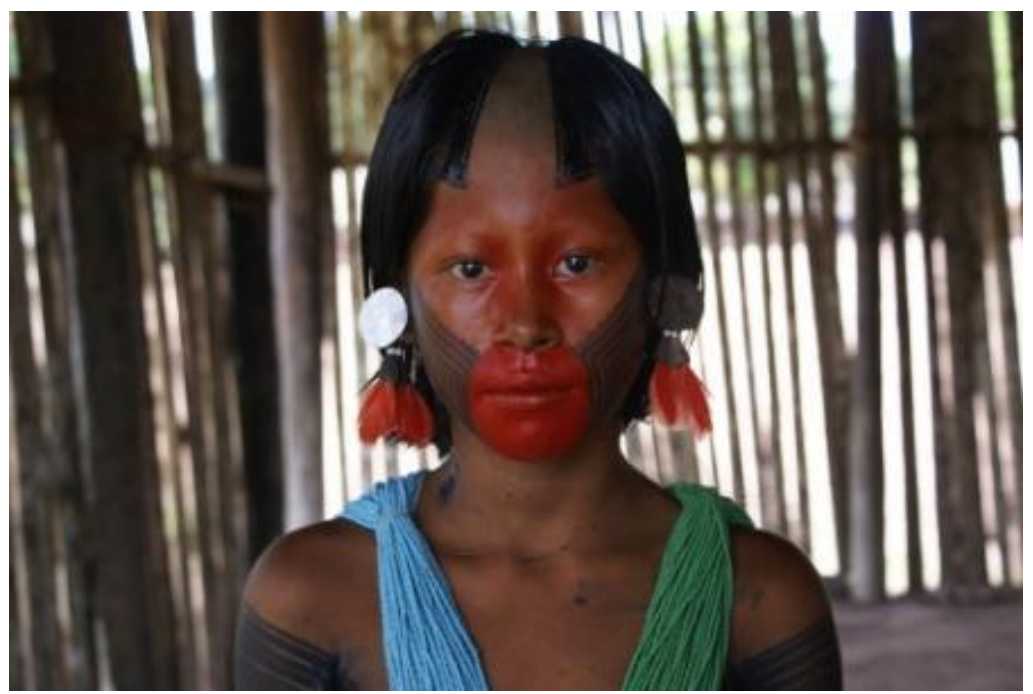

Figura 3-Corte de cabelo Kayapó (Luis Carlos S. Sampaio, 2010).

As guerras entre as tribos do complexo cultural do Xingu e as outras da periferia da área, mostram que as mulheres são cobiçadas, alvo de raptos e de agressões sexuais. As mulheres são consideradas um ponto vulnerável da sociedade e face às forças espirituais que as rodeiam. Observa-se a ligação entre a mulher, cabelo, sexo e outras atitudes agressivas. Informantes dessa tribo disseram que seus antepassados não cortavam os cabelos, penteando-os 
diariamente. Untam-nos com óleo de babaçu (uma palmeira) para torná-los macios.

\section{PLUMÁRIA MEBENGOKRÊ}

A arte plumária é um termo que designa artefatos confeccionados a partir de penas de aves e utilizados, sobretudo, como adorno corporal pelos índios brasileiros.

Observa-se que muitas tribos desenvolveram estilos próprios, caracterizados por atributos peculiares como formas, associação de matérias, combinação de cores, procedimento técnico, o que nos permite identificar a sua proveniência com bastante precisão.

Os adornos plumários não servem apenas para enfeitar o corpo, e 0 elemento plumário aplicado a outras superfícies, como armas, instrumentos, musicais, máscara, não podem ser vistos apenas como atributo meramente decorativo. São considerados verdadeiros códigos que transmitem, numa linguagem não verbal, mensagens sobre sexo, idade, filiação clânica, posição social, importância cerimonial, cargo político e grau de prestígio de seus portadores.

Além de enfeites, portanto, são símbolos e, por isso, usados nos ritos e cerimônias, campo simbólico por excelência das culturas humanas. (DORTA e VELTHEM, 1982).

A ornamentação do corpo uma das características mais originais da cultura Kayapó. Parece ser possível afirmar que entre esses indígenas a ornamentação Ihes confere o status de ser humano em contraposição aos seres vivos e especialmente para o Kayapó. É interessante observar que o mesmo ornamento varia em forma e tamanho de um grupo Kayapó para outro, tornando possível a identificação dos diferentes subgrupos. 
A plumária Kayapó é usada essencialmente durante os grandes rituais de nomeação e iniciação masculina, no casamento, na esteira e paramentação do morto durante os ritos de passagem. De modo geral, os enfeites de pena se relacionam com a vida cerimonial em oposição ao cotidiano, quando prevalece a pintura corporal como único adorno do corpo.

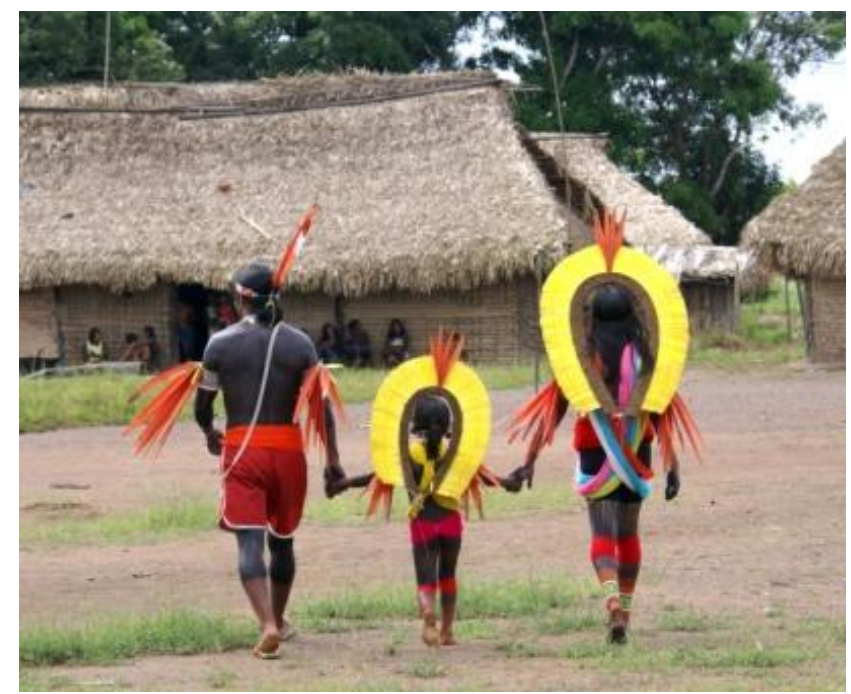

Figura 4- Família adornada por artefatos plumários (Luis Carlos da Silva Sampaio, 2010).

A arte plumária é extremamente variada, como cocares, testeiras e diademas, usam penas na confecção de braçadeiras, pulseiras, bandoleiras, ornamentos dorsais e flechas. O uso de penugem branca de urubu-rei colada no cabelo é um adorno típico destes grupos. A procura das penugens ocorre durante as caçadas indígenas, desse modo, procuram aves cujas penas são escolhidas e separadas adequadamente. Assim, na ocasião da confecção, o artesão possui a sua disposição uma grande variedade de matéria prima que se adapta a cada tipo de objeto a ser confeccionando.

Alguns ornamentos, como o grande diadema Krokrok ti, possuem denso significados simbólicos. Entre os Kayapó-Xikrin do rio Catete, por exemplo, ele pode representar um olho, sendo as penas as pestanas, ou representar, em outro contexto, o sol, passando as penas a representar os raios. Mas simboliza, 
antes de mais nada, a forma circular de uma aldeia onde as penas azuis, centrais, representam a praça, o lugar masculino e ritual por excelência, a fileira de penas vermelhas, a periferia, as casas, o mundo doméstico e das mulheres, e as penugens brancas amarradas nas pontas e a floresta, (VIDAL, 1982). A disposição e as cores das penas do cocar, adorno usado preso na cabeça, as cores das penas do cocar não são aleatórias. Além de bonito, ele indica a posição de chefe dentro do grupo e simboliza a própria ordenação da vida em uma aldeia Kayapó, em forma de arco, uma grande roda a girar entre o presente e o passado.

O verde sugere a representação das matas, que protegem as aldeias e ao mesmo tempo elas são a morada dos mortos e dos seres sobrenaturais. As matas são consideradas um lugar perigoso, já que fogem ao controle dos Kayapó. O amarelo refere-se às casas e às roças, áreas dominadas pelas mulheres. Nesses espaços, elas pintam os corpos dos maridos e dos filhos, plantam, colhem e preparam os alimentos. Todas as choças têm a mesma distância em relação à casa dos homens. A cor mais forte é o vermelho, representa a casa dos homens, que fica bem no coração da aldeia. Ali eles se reúnem diariamente para discutir caçadas, guerras, rituais e confeccionar adornos, como colares e pulseiras, explica Luis Grupioni.

\section{RITUAIS KAYAPÓ}

Os rituais Kayapó são numerosos e diversos, mas sua importância e duração variam fortemente. Dividem-se em três categorias principais: as grandes cerimônias de confirmação de nomes pessoais; certos ritos agrícolas, de caça, de pesca e de ocasião - por exemplo, aqueles realizados quando de um eclipse solar ou lunar - e, enfim, os ritos de passagem, estes são freqüentemente solenes, porém raramente acompanhados de danças ou 
cantos: são organizados para anunciar publicamente a passagem de algumas pessoas de uma classe de idade para a outra.

Exemplos de ritos de passagem, todas as cerimônias são qualificadas pelo termo mereremex ("gente que estende a sua beleza"), que são crianças "honradas". As crianças honradas são auxiliadas por dois ou mais amigos rituais, pessoas não-aparentadas de ambos os sexos que sempre terão como tarefa auxiliar essa criança quando de todas as fases difíceis de sua vida futura. (VERSWIJVER, 1992).

Tais cerimônias constituem atividades grupais cuja finalidade é socializar valores "selvagens" ou anti-sociais. É assim em relação à atribuição do nome, tema central da maior parte das cerimônias Kayapó; com efeito, os nomes pessoais são emprestados da natureza. São os xamãs que entram em contato com os espíritos naturais e aprendem com eles novos cantos e nomes. Esses nomes, ao lado dos cantos aos quais eles se referem, são elementos emprestados do mundo "natural", devendo, então, ser introduzidos na cultura no momento das grandes cerimônias de nominação.

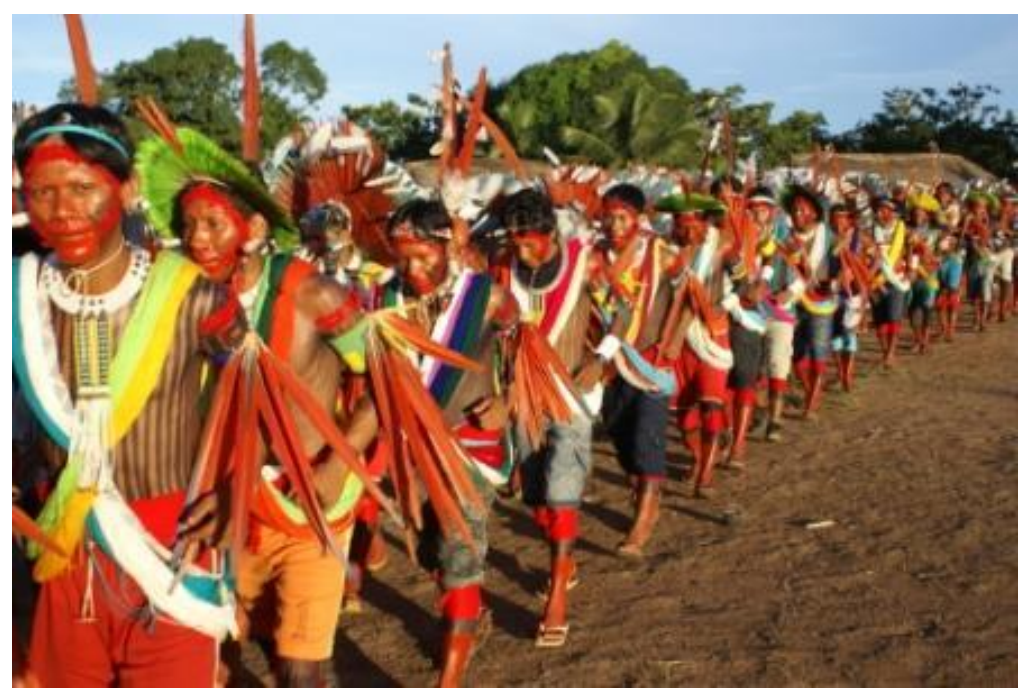

Figura 5- Festa dos Homens, Memybiôk, aldeia Kubenkokre (Luis Carlos S. Sampaio, 2010). 


\section{CULINÁRIA MEBENGOKRÊ}

No que se refere à arte culinária Kayapó, destacam-se os alimentos assados no forno, pois esses povos não apreciam comida na água. Hoje, os Kayapó usam panelas de alumínio para carregar água ou para cozinhar o arroz ou macarrão, produtos comprados na cidade. Porém, as carnes, o peixe, a mandioca, o milho, o palmito e as abóboras, assim como os grandes bolos de farinha de mandioca embrulhados em folhas de bananeiras denominado Juwocupú, são assados diariamente no grande forno de pedra o Ki situado atrás das casas na aldeia. Ele faz parte integrante da vida dos Kayapó e não se pode imaginar sua aldeia sem ele. A construção e o manejo do forno são tarefas das mulheres, especialmente quando há muito alimento para assar as mulheres se reúnem e tratam do forno e da comida. O forno Kayapó funciona, basicamente, como um forno de carvoeiro. Prepara-se primeiro um braseiro, ao mesmo tempo, esquenta-se dentro dele uma série de pedras lisas e arredondadas tiradas do rio. Quando a brasa está boa e as pedras bem quentes, colocam-se as comidas. Essas são embrulhadas em folhas de bananeiras para que os alimentos não se ressequem, não tomem gosto de fumaça ou fiquem sujos de terra. Cada mulher coloca assim a comida preparada por ela o que é quase sempre o sustento do dia para a família. 


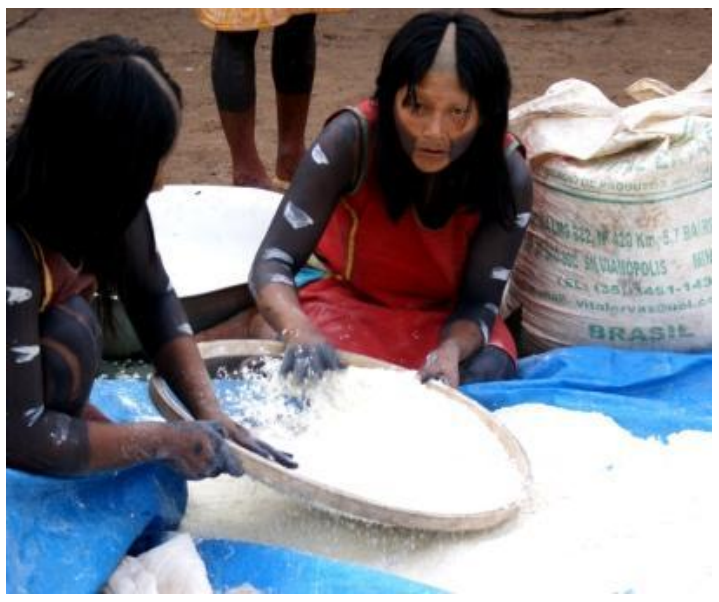

Figura 6- Elabora massa de farinha para Juwocupú o grande bolo de farinha de mandioca embrulhado em folhas de bananeira, com pedaços de carne de caça ou peixe (Luis Carlos $\mathrm{S}$. Sampaio, 2010).

\section{CONSIDERAÇÕES FINAIS}

As populações indígenas sempre foram vistas de forma etnocêntrica pelos não índios passando a existir o preconceito e a idealização. "Por maior que seja o empenho em salvar as populações tribais num mundo em que a civilização se expande com crescente rapidez, não há como evitar que as suas culturas se transformem, de geração em geração, pela presença do homem branco" (GIACCARIA \& HEIDE, 1975).

A sociedade Kayapó percebe o mundo de forma cíclica e sua visão se manifesta em riquíssimas expressões culturais, que incorporam os grafismos produzidos pelo corpo, danças, adornos, cantos, que misturam em cores, espaço, simbologia e valiosos olhares sobre a conservação de suas terras que mantém grande parte da floresta Amazônica.

Nesse sentido, a natureza, seu ambiente está presente no seu universo cromático, no ciclo de vida e morte em que o preto e o vermelho se manifestam 
inconscientemente. Ao conhecer a arte, cultura e costumes Kayapó, percebese o forte simbolismo que eles estabelecem com a natureza, onde a beleza e a elegância coexistem com a floresta. Sua arte reflete todo um código complexo de comunicação que é perpetuado pela cultura. Assim, o povo Kayapó exprime a sua concepção de grupo, sua percepção individual, suas relações com os outros índios, sua subjetividade e principalmente o seu respeito à natureza.

\section{REFERÊNCIAS}

BELTRÃO, Luiz, REINER, Sylvio, GUIMRRÃES, Ernesto. Revista de atualidade indígena: ano1;n³,ำ5,4,2. Brasília, 1977.

BRASIL, Tribunal regional Federal. Proc.n-95.000063-4 de Francisco Scarpa; Laudo Antropológico, Metuktire, Capoto.Jarina,1998.

FUERST, René.Xikrin Hommes Oiseaux D' Amazonie: 5 Continents/Milan, 2006.

GIACARIA \& HEIDE, Bartolomeu, Adalberto. Jerônimo Xavante Conta Mitos e lenda: Casa da Cultura. Campo Grande, 1975.

LEITE, Maria Eliza. Atlas dos territórios Mebêngõkre, Panará e Tapajúna: Associação IPREN-RE de defesa do povo Mebêngõkre. FUNAIIAER. Colider, 2007. 
DORTA, Sonia e VELTHEM, Lúcia, $\mathbf{A}$ temática indígena na escola: novos subsídios para professores de $1^{\circ}$ e $2^{\circ}$ graus. org. MEC $\backslash$ MARI UNESCO Brasília,1995.

MACEDO, Sergio. Xingu. São Paulo: Devir, 2007.

VIDAL, Lux, A temática indígena na escola: novos subsídios para professores de $\mathbf{1}^{\circ}$ e $\mathbf{2}^{\circ}$ graus. org. Brasília, MECIMARIUUNESCO,1995.

VERSWIJVER, Gustaaf, Kaiapó. Museu Real da África Central,Snoeck- Ducaju \& Zoon, Gent, 1992.

TURNER, Terence, Estrutura social e organização política entre os caiapós do Norte. Ph.D. tese. Cambridge: Harvard University,1966.

TURNER, Terence, Os Mebengokre Kayapó: história, consciência social e mudança social das comunidades autónomas do sistema inter-étnica. Manuscrito não publicado. Departamento de Antropologia. Universidade de Chicago, 1991. 337pp.

ZIMMERMAN, B.L., C.A. PERES, J.R. MALCOLM AND T. TURNER. Conservation and development alliances with the Kayapó of southeastern Amazonia, a tropical forest indigenous people. Environmental Conservation 28 (1), 2001.

Fotos do acervo pessoal de Luis Carlos da Silva Sampaio, ano 2010. 